\title{
Initial adherence of EPEC, EHEC and VTEC to host cells
}

\author{
Marjorie BARDIAU $^{1 *}$, Mihai SzAlO ${ }^{2}$, Jacques G. MAINIL ${ }^{1}$ \\ ${ }^{1}$ Department of Infectious and Parasitic Diseases, Bacteriology, Faculty of Veterinary Medicine, \\ University of Liège, Liège B4000, Belgium \\ ${ }^{2}$ Department of Bird, Rabbit and Rodent Medicine, Faculty of Veterinary Medicine, \\ University of Liège, Liège B4000, Belgium
}

(Received 14 September 2009; accepted 27 April 2010)

\begin{abstract}
Initial adherence to host cells is the first step of the infection of enteropathogenic Escherichia coli (EPEC), enterohaemorrhagic Escherichia coli (EHEC) and verotoxigenic Escherichia coli (VTEC) strains. The importance of this step in the infection resides in the fact that (1) adherence is the first contact between bacteria and intestinal cells without which the other steps cannot occur and (2) adherence is the basis of host specificity for a lot of pathogens. This review describes the initial adhesins of the EPEC, EHEC and VTEC strains. During the last few years, several new adhesins and putative colonisation factors have been described, especially in EHEC strains. Only a few adhesins (BfpA, AF/R1, AF/R2, Ral, F18 adhesins) appear to be host and pathotype specific. The others are found in more than one species and/or pathotype (EPEC, EHEC, VTEC). Initial adherence of EPEC, EHEC and VTEC strains to host cells is probably mediated by multiple mechanisms.
\end{abstract}

adherence / adhesin / enteropathogenic $E$. coli / enterohaemorrhagic $E$. coli / verotoxigenic $E$. coli

\section{Table of contents}

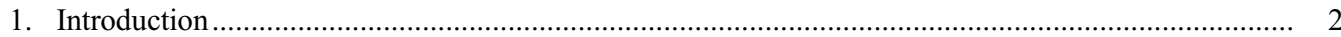

1.1. Enteropathogenic, enterohaemorrhagic and verotoxigenic Escherichia coli .......................... 2

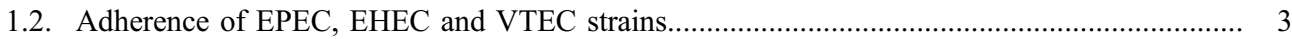

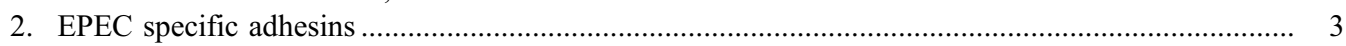

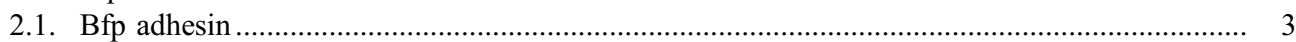

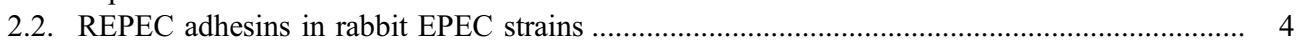

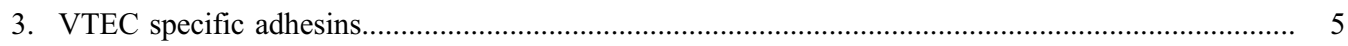

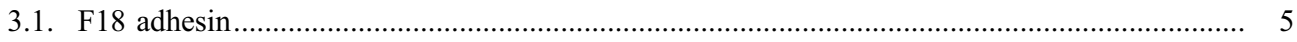

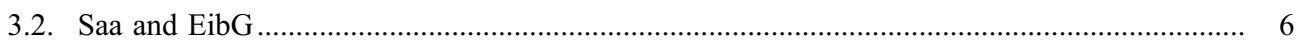

4. Adhesins present in more than one of the three pathotypes ....................................................... 7

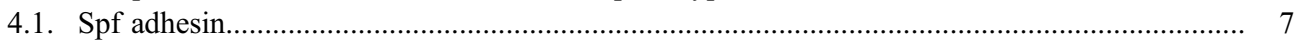

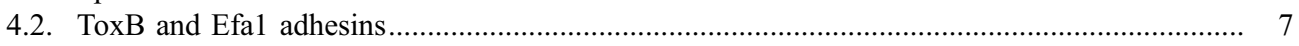

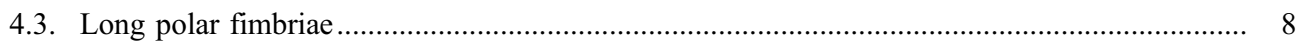

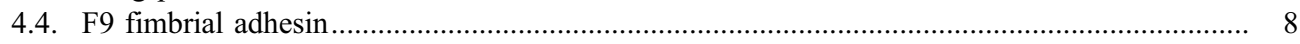

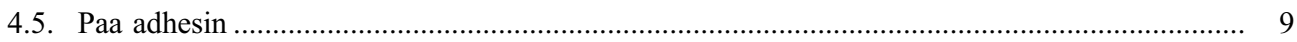

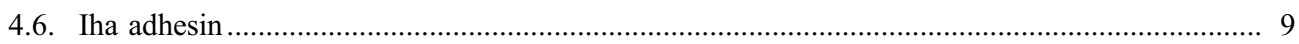

\footnotetext{
* Corresponding author: mbardiau@ulg.ac.be
} 
4.7. AIDA adhesin

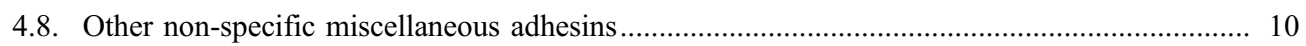

5. Concluding remarks.

\section{INTRODUCTION}

\subsection{Enteropathogenic, enterohaemorrhagic and verotoxigenic Escherichia coli}

The Escherichia coli species is a Gramnegative bacterium that belongs to the Enterobacteriaceae family. It is the predominant facultative anaerobe of the human colonic flora. However, some strains have developed the ability to cause disease of the gastrointestinal, urinary, or central nervous system. Pathogenic gastrointestinal strains of $E$. coli are classified according to the properties of their virulence: enteropathogenic E. coli (EPEC), enterotoxinogenic E. coli (ETEC), enterohaemorrhagic E. coli (EHEC), enteroinvasive E. coli (EIEC), enteroaggregative E. coli (EAEC), verotoxinogenic $E$. coli (VTEC), "diffusely adherent" E. coli (DAEC), necrotoxinogenic E. coli (NTEC) [77].

The main virulence property of EPEC strains is the production of a specific lesion called "attaching and effacing (A/E) lesion" characterised by loss of microvilli and intimate attachment of the bacteria to the host [71], whereas the main virulence property of VTEC is the production of verotoxins (or shiga-toxins) that are lethal for eukaryotic cells [56]. As for EHEC strains, their main virulence properties are the production of $\mathrm{A} / \mathrm{E}$ lesions and verotoxins [23].

EPEC strains colonise the small intestine and cause profuse watery diarrhoea in humans. They were responsible for frequent outbreaks of infant diarrhoea in the USA and the United Kingdom in the 1940s and 1950s [92]. In contrast to the limited importance of EPEC in developed countries nowadays, EPEC are still a major cause of child diarrhoea in developing countries, especially in infants younger than 2 years. The death rate in developed countries is low today but it can reach up to $30 \%$ in developing countries [77, 96]. Transmission occurs via oral-faecal contact with contami- nated hands or foods. According to epidemiological surveys, asymptomatic carriage by humans could also be at the root of contamination [77]. In bovines, infection with EPEC strains is associated with diarrhoea in young calves (1 week to 8 weeks old) [32]. There is no mortality in calves, but diarrhoea can become chronic, causing economic loss as a consequence. In addition to human and bovine infections, EPEC strains are also found in dogs, cats, rabbits, pigs, goats, and sheep [57]. In rabbits, EPEC strains infect neonates and recently weaned animals causing mild to severe diarrhoea, with important economic loss [17]. In dogs, cats and piglets, colonisation by EPEC strains can occasionally lead to diarrhoea. Finally, in goats and sheep, EPEC strains can be found but the association with diarrhoea has not yet been demonstrated [68].

Infections by EHEC strains in humans are characterised by the production of diarrhoea generally accompanied by haemorrhagic colitis (HC) with, in a few percent of cases, renal sequelae (haemolytic uremic syndrome, HUS), which can lead to death. EHEC strains were recognised as a distinct class of pathogenic E. coli in 1983 after two outbreaks in the USA [124]. Today, they represent an important problem for public health in developed countries all over the world. The most common EHEC serotype is O157:H7, but other serogroups such as O26, O111, O145 and O103 are also very important in some countries. In the USA, O157:H7 have been estimated to cause 73000 illnesses annually and non-O157 EHEC serotypes, at least 37000 illnesses [19]. In Europe and Japan, infection by EHEC also has a real importance as a foodborne disease [23]. In the veterinary field, several serogroups of the EHEC strain (O26, O111, O118 for example) are directly associated with diarrhoea in 2 week to 2 month old calves $[46,73]$. The consequences are economic losses due to a delay in growth and weakness of 
calves. EHEC strains can also be found in the faecal flora of a wide variety of animals (cattle, sheep, goats, pigs, cats, dogs, chickens, and gulls) [70]. Cattle, other domestic ruminants and wild ruminants are the most important animal species in terms of a reservoir for human infection and are mainly responsible for food contamination [46]. Indeed, in many cases, EHEC strains infect man via vegetal and animal food soiled by ruminant faeces. Other wellrecognised sources of contamination are secondary transmissions from infected persons $[88,93]$.

VTEC strains cause pathology mainly in humans and piglets. But they can also be found in a large spectrum of domestic and wild animals [126]. In humans, VTEC infections are not frequent but, when they occur, they are frequently associated with HUS syndrome. In piglets, VTEC strains are responsible for oedema disease up to two weeks after weaning [74].

\subsection{Adherence of EPEC, EHEC and VTEC strains}

Pathogenicity of EPEC infection can be tentatively divided into three stages [31]: (1) initial adherence and colonisation of the intestine; (2) translocation of bacterial signals into the eukaryotic cells via a type III secretion system that cause cytoskeleton rearrangements in enterocytes; and (3) intimate adherence of bacteria to eukaryotic cells by specific proteins, the intimins (coding by the eae gene). Steps 2 and 3 together cause the formation of $\mathrm{A} / \mathrm{E}$ lesions. For EHEC infection, a fourth step consists of the production of verotoxins. For VTEC infection, steps 2 and 3 do not exist and verotoxins are produced after intestinal colonisation.

The molecular biology of the production of $\mathrm{A} / \mathrm{E}$ lesions and the action of verotoxins is today quite well described and understood, even if research remains to be performed to fully understand the in vivo pathogenesis of those strains. On the contrary, the step of intestinal colonisation via specific adhesins initiating the interaction between the bacteria and host tissues and anchoring the bacteria onto the surface of the enterocytes is actually still poorly understood for many strains [120]. The importance of initial adherence in the infection resides in the following: (1) adherence is the first contact between bacteria and intestinal cells without which the other steps cannot occur, (2) adherence is the basis of host specificity for a lot of pathogens, (3) adhesins represent a good target for the development of a specific vaccinal prophylaxis [25].

The aim of this review is to describe the initial adhesins of the EPEC, EHEC and VTEC strains (Tab. I). During the last few years, several new adhesins and putative colonisation factors have been described, especially in EHEC strains $[64,65,78,107,127]$. First, this review will describe pathotype (EPEC, EHEC or VTEC) specific adhesins. Then, adhesins present in more than one of the three pathotypes will be described.

\section{EPEC SPECIFIC ADHESINS}

\subsection{Bfp adhesin}

\subsubsection{Description}

In 1991, Gìron et al. [41] showed that EPEC strains express rope-like bundles of filaments, termed bundle-forming pili (BFP), which create a network of fibres that bind the individual bacteria together. An antiserum against BFP reduces the capacity of EPEC to infect cultured epithelial cells. The $b f p A$ gene codes for the main subunit. It is part of an operon of 14 genes: $b f p A$ (the pre-pilin), $b f p B$ (a lipoprotein), $b f p C$ (a bitopic cytoplasmic membrane protein), $b f p D$ (a hexameric cytoplasmic ATPase), $b f p E$ (a polytopic cytoplasmic membrane protein), $b f p F$ (a putative cytoplasmic nucleotide-binding protein), $b f p G$ (an unknown function protein that interacts with bfpB), $b f p H$ (an unknown function protein that is perhaps not expressed), $b f p I$ (a pre-pilin-like protein), $b f p J$ (a pre-pilinlike protein), $b f p K$ (a pre-pilin-like protein), $b f p L$ (a protein localised with both the inner and outer membranes), $b f p P$ (a pre-pilin peptidase) and $b f p U$ (an unknown function protein that interacts with $b f p B)[28,30,100,103]$. This operon is situated on a 50-70 MDa plasmid called EPEC Adherence Factor (EAF). 
Table I. Distribution of the main adhesins present in EPEC, EHEC and VTEC strains.

\begin{tabular}{lcc}
\hline Adhesin & $\begin{array}{c}\text { Present in } \\
\text { pathotypes }\end{array}$ & Host \\
\hline Bfp & EPEC & Human, dog \\
AF/R1 & EPEC & Rabbit \\
AF/R2 & EPEC & Rabbit \\
Ral & EPEC & Rabbit \\
F18 & VTEC & Pig \\
Saa & VTEC & Human, cattle, \\
& & sheep \\
EibG & VTEC & Human \\
Spf & EPEC, EHEC & Human, cattle \\
Efa1 & EPEC, EHEC & Human, cattle \\
ToxB & EPEC, EHEC, VTEC & Human, cattle \\
Lpf & EPEC, EHEC, VTEC & Human, cattle \\
F9 & EPEC, EHEC & Human, cattle \\
Paa & EPEC, EHEC & Human, pig, cattle \\
Iha & EPEC, EHEC, VTEC & Human, pig, cattle \\
AIDA & EPEC, VTEC & Human, pig \\
\hline
\end{tabular}

The presence of the $b f p A$ gene has been searched for in human and animal EPEC, EHEC and VTEC strains but also in Salmonella sp. serotypes [23, 25, 41, 42, 55, 99, 122]. The gene was only detected in a subclass of human EPEC strains and in a few EPEC strains from dogs, but not in other EPEC, EHEC and VTEC strains. Human EPEC strains harbouring the EAF plasmid are called "typical-EPEC" strains (t-EPEC) and other human EPEC strains that do not carry EAF plasmid are known as "atypicalEPEC" strains (a-EPEC) [119].

\subsubsection{Involvement in the adherence}

The plasmid containing the Bfp operon is responsible for the localised adherence (LA) phenotype on cell culture [3]. The complementation of a non-adherent $E$. coli strain with the EAF plasmid leads to an increase in adherence to epithelial cells. In 1985, Levine et al. [63] had already observed the importance of the plasmid during infection in vivo. EPEC strain E2348/69 (containing the EAF plasmid) and its mutant cured of EAF plasmid was inoculated into 10 volunteers. Diarrhoea occurred in nine out of the 10 volunteers who ingested the parental strain but in only 2 of the 9 who took the mutant. The $b f p$ cluster is regulated by environmental signals such as temperature, calcium and ammonium [86]. These findings support the pathogenic role of BFP by the initiation of BFP production in the small intestine, but not in the colon and external habitats.

Adherence studies on mouse and human eukaryotic cells have indicated that BFP play an important role in the cell-type-dependent adherence of t-EPEC [111]. Indeed, the adherence of the bacteria is lower on mouse-derived cells than on human-derived cells. BFP are also implicated in biofilm formation. Moreira et al. [72] demonstrated that the genes encoding BFP are expressed during biofilm formation and that mutants that do not express BFP form more diffuse biofilms than does the wild type strain.

The Bfp adhesin contributes to the attachment of the bacteria to eukaryotic cells but does not seem to be necessary to cause disease in humans. Indeed, the a-EPEC strains (that do not carry the $b f p A$ gene) are more and more implicated in diarrhoea outbreaks in both developed and developing countries. Various other adhesins (f.i. Paa, LpfAO113, Iha, Ehx, ToxB, $\mathrm{LdaG}$ ) are present in a-EPEC strains [45] and play probably the same role as Bfp in adherence. Nevertheless, Bfp adhesin seems to be host specific considering that the $b f p A$ gene is mostly found in strains isolated from humans. This host specificity could be explained by the fact that the $b f p$ cluster is regulated by environmental signals [86] and that human intestines differ from animal intestines [43].

\subsection{REPEC adhesins in rabbit EPEC strains}

\subsubsection{Description}

Three different rabbit-specific adhesins exist in rabbit EPEC strains (REPEC): Adhesive factor/Rabbit 1 (AF/R1) [12], Adhesive factor/ Rabbit 2 (AF/R2) [38], Ral [1].

The operon of AF/R1 adhesin is composed of seven genes: afrA (the structural subunit), $a f r B$ (an usher protein), afrC (a chaperone), afrD (an adhesin), afrE (an unknown function protein), afr $R$ and afr $S$ (two transcriptional regulators). afr $A, a f r B$ and $a f r C$ genes are required 
for the expression of the pilus and for the adherence to the host cells and afrD and afrE genes are only required for the adherence to the host cells [22]. Penteado et al. [83] and Dow et al. [33] studied the prevalence of the AF/R1 adhesin and respectively found the adhesin in $0 \%$ and $4.7 \%$ of the REPEC (only found in O103:H2 serotype strains).

Fiederling et al. [38] cloned the afr 2 operon and showed that the afr $2 G$ gene (the major subunit) is homologous to $\operatorname{clp} G$ from the CS31A adhesin and fae $G$ from the K88 (F4) adhesin. Penteado et al. [83] and Dow et al. [33] studied the prevalence of the AF/R2 adhesin and respectively found the adhesin in $83.3 \%$ and $23.3 \%$ of the REPEC of O103:H2, O132:H2, O153:H7, O126:H-serotypes.

Ral adhesin is coded by an operon situated on the $95 \mathrm{~kb}$-pRAP plasmid (REPEC adherence plasmid) and is homologous to $\mathrm{K} 88$, $\mathrm{CS} 31 \mathrm{~A}$ and $\mathrm{AF} / \mathrm{R} 2$ adhesins. The operon is composed of seven genes: ralC, ralF and $\mathrm{ralH}$ (three putative minor subunits); ralG (one putative major subunit); rall (an unknown function protein); ralD and ralE (two chaperones). Dow et al. [33] studied the prevalence of the Ral adhesin and found that this adhesin is present in $35 \%$ of the REPEC of O153:H7, O15, O132:H2, O49:H2, O145 serotypes.

\subsubsection{Involvement in the adherence}

$\mathrm{AF} / \mathrm{R} 1$ was first described by Berendson et al. [12]. In their experiments, they infected sections of human, guinea pig, rat and rabbit small intestines with an REPEC positive for AF/R1 and its deleted mutant and they detected the adherence by indirect immunofluorescence technique. The piliated REPEC strain fully adhered only to the rabbit section and only a few colonies of the non-piliated REPEC strain adhered to the small intestine section in comparison with the wild type. Rafiee et al. [87] identified a rabbit ileal microvillus membrane sialoglycoprotein complex with subunits of 130 and $140 \mathrm{kDa}$ as a receptor(s) for $\mathrm{AF} / \mathrm{R} 1$ fimbriae localised on the rabbit small intestine [94].

$\mathrm{AF} / \mathrm{R} 2$ was first described in an REPEC O103 strain by Pillien et al. [85]. This adhesin gives the capacity of diffuse adherence (DA) to rabbit enterocytes and HeLa cells and there is a loss of pathogenicity after inoculation of deleted mutants into the rabbit.

Mutants deleted in the Ral operon show a 10 times lower colonisation of the rabbit intestine and a decrease in the severity of the disease in vivo [1]. Krejany et al. [58] showed that the adherence on the intestinal rabbit loop is lost with a mutant deleted in Ral adhesin.

As for BFP, REPEC adhesins appear to play a role in the attachment of bacteria to eukaryotic cells and seem to be host specific. AF/R1 binds specifically to a sialoglycoprotein complex. This receptor could vary among species as it has already been shown previously [87].

\section{VTEC SPECIFIC ADHESINS}

\subsection{F18 adhesin}

\subsubsection{Description}

In 1995, Rippinger et al. [91] designated two variants (F18ab and F18ac) that correspond to the related fimbrial types F107 [13], 2134P [76] and 8813 [95] of verotoxigenic and enterotoxigenic E. coli isolated, respectively, from porcine postweaning diarrhoea and oedema disease. The F18ab variant is mostly associated to the VTEC strains while the F18ac variant is mostly associated to the ETEC strains [26]. This fimbria is a long flexible filament with a maximum $4.6 \mathrm{~nm}$ diameter. Mainil et al. [69] showed that the F18 gene is localised on the same plasmid as the adhesin involved in diffuse adherence (AIDA) in E. coli isolated from piglets. The operon coding for this fimbria is composed of five genes: $f e d A, f e d B, f e d C, f e d E$ and fedF $[47,48,98]$. The backbone is built from the major subunit, FedA $(15.1 \mathrm{kDa})$; but this subunit is not sufficient for recognising the F18 receptor [47]. FedE (15.9 kDa) and FedF $(30.1 \mathrm{kDa})$ are two minor subunits and are essential for fimbrial adherence $[48,98]$. Smeds et al. [98] showed that the FedF protein plays the role of the adhesin of the F18 fimbriae. Indeed, anti-FedF antibodies, unlike anti-FedE serum, are able to inhibit $E$. coli adherence to porcine enterocytes. Moreover, subunit FedF is highly conserved among $\mathrm{F} 18+E$. coli 
isolates (from different countries and from the two different variants) [109]. FedB (86 kDa) and FedC $(23.4 \mathrm{kDa})$ act respectively in the biosynthesis of the pili and as a chaperone. Several laboratories studied the distribution of the F18 adhesin in a collection of strains. Zweifel et al. [133] searched for the $f e d A$ gene in 31 VTEC strains isolated from healthy pigs at slaughter and only one strain was positive for this gene. Cheng et al. [26] looked for the presence of $\mathrm{F} 18 \mathrm{ab}$ and $\mathrm{F} 18 \mathrm{ac}$ variants in VTEC, VTEC/ETEC and ETEC strains isolated from diarrheic piglets. They found F18ab and F18ac adhesins in respectively $62 \%$ and $0 \%$ of VTEC, in $62.5 \%$ and $33 \%$ of VTEC/ETEC strains and in $4 \%$ and $8 \%$ of ETEC strains. Osek et al. [81] found the $\mathrm{fedA}$ gene in $2.7 \%$ of strains isolated from diarrheic piglets and in $2.2 \%$ of strains isolated from healthy piglets.

\subsubsection{Involvement in the adherence}

Several studies have shown that this adhesin allows adherence to microvilli of piglet enterocytes [76, 95, 129, 131]. The F18 receptor (F18R) plays an important role in the VTEC/ ETEC infection. Piglets can possess $(\mathrm{F} 18 \mathrm{R}+)$ or not the receptor $(\mathrm{F} 18 \mathrm{R}-)$ and only those piglets that do possess the receptor are subject to infection with F18+E. coli [40]. The F18R status of pigs is genetically determined [14] and, recently, Coddens et al. [27] have shown that the expression of the F18 receptor is positively correlated with the presence of histo-blood group antigens, that its levels rise with increasing age during the first 3 weeks after birth and that F18 receptor expression is maintained in older pigs (3-23 weeks old). Several laboratories have tried to develop vaccines against F18 fimbria to prevent post-weaning diarrhoea in piglets $[15,35,110,123]$.

\subsection{Saa and EibG}

\subsubsection{Description}

In 2001, Paton et al. [82] isolated a gene, named saa (STEC autoagglutinating adhesin), from the megaplasmid of an eae-negative O113:H21 VTEC strain (98NK2) responsible for an outbreak of HUS in Australia. In the
98NK2 strain, the protein is 516 amino-acids long, including four copies of a 37-aa direct repeat sequence, and is localised in the outer membrane of the cell. Saa produced by other VTEC strains vary in size as a consequence of variation in the number of copies of a 37-aa repeat unit. In 2006, Lucchesi et al. [67] found the existence of 5 variants based on this variation in the number of repeat units present in the $3^{\prime}$ coding region. Saa exhibits $24-27 \%$ of identity with two outer membrane proteins, YadA of Yersinia enterocolitica (a plasmid-encoded outer membrane protein implicated in epithelial cell adherence and invasion) and Eib of E. coli (E. coli immunoglobulin-binding protein) [82]. Several laboratories have studied the distribution of the saa gene in a collection of strains $[18,24,50,80,112$, 132]. The saa gene was found in VTEC strains isolated from cattle, humans, sheep and food. There always exists a negative correlation between the presence of the saa gene and the gene coding for intimin (eae gene).

In 2006, Lu et al. [66] identified a new gene designated $e i b G$ through the screening of transposon-mutagenised O91 E. coli. The gene encodes a 508-amino-acid protein that presents similarity to Eib proteins (E. coli immunoglobulin-binding protein). Lu et al. [66] examined the distribution of $e i b G$ in human $\mathrm{O} 157, \mathrm{O} 26, \mathrm{O} 111$ and 091 strains. All eae-positive and saa-positive strains were found to be negative for $e i b G$.

\subsubsection{Involvement in the adherence}

Paton et al. [82] showed that the introduction of the saa gene cloned into a plasmid increases 9.7 fold the adherence of $E$. coli JM109 to HEp-2 and a semilocalised adherence pattern. Mutagenesis of this gene in the O113:H21 strain reduces the adherence significantly. The saa gene encodes an auto-agglutinating adhesin. In 2008, Toma et al. [114] showed that saa-positive VTEC strains exhibit differential binding properties to HEp-2 and Caco-2 cells. On the 32 strains studied for their adherence to epithelial cells in the absence or presence of D-mannose, 13 strains were sensitive to the presence of this sugar. Moreover, a VTEC strain (in which adherence was mannose 
resistant) was deleted in the saa gene and its adherence to epithelial cells was not significantly decreased compared to the wild type, suggesting that multiple adherence mechanisms are present in saa-positive VTEC strains.

EibG is a new immunoglobulin-binding protein and acts as an adhesin in certain strains of VTEC. A mutant deleted in the eibG gene was constructed and its adherence phenotype was studied on Hep-2 cells. The mutant did not adhere to epithelial cells and the chain-like adherence pattern (CLA pattern) was restored after the transformation of the mutant with a plasmid carrying only eibG. Therefore, Lu et al. [66] suggested that the $e i b G$ gene is responsible for the CLA pattern.

Saa is present in several species and do not seem to be host specific but is present only in eae-negative, stx-positive strains and interestingly in $e i b G$-negative strains. VTEC strains do not carry the eae gene and thus may compensate for this lack by a multiple adherence mechanism.

\section{ADHESINS PRESENT IN MORE THAN ONE OF THE THREE PATHOTYPES}

\subsection{Spf adhesin}

\subsubsection{Description}

The first fimbria to have been described in EHEC strains was part of a cluster called $s f p$ (sorbitol-fermenting protein) encoded by a large plasmid in sorbitol-fermenting O157 strains [20]. This fimbria has similarities with the pap gene, which codes for the P-fimbriae in uropathogenic $E$. coli strains. The cluster is divided into six genes: $s f p A$ (the major pilin), $s f p H$, $s f p C, s f p D, s f p J$, and $s f p G$ (the adhesin). Several studies showed that $s f p A$ is present only in sorbitol-fermenting O157 strains (EHEC and EPEC strains isolated from humans with diarrhoea and HUS) [21, 39, 49]. In 2006, Lee et al. [61] detected spfA in sorbitol-fermenting $\mathrm{O} 157$ strains isolated from cattle. Recently, Bielaszewska et al. [16] detected the entire cluster in EHEC O165:H25/NM strains isolated from cattle and humans and they suggested that this cluster is acquired indepen- dently by EHEC O165:H25 and sorbitolfermenting EHEC O157:NM.

\subsubsection{Involvement in the adherence}

A mutant deleted in the $s f p$ gene is not more able to agglutinate erythrocytes. The expression of Sfp and the adherence to Caco-2 and HCT8 cells are increased in anaerobic conditions that imitate intestinal conditions [75]. It has, therefore, been suggested that Sfp production is induced under conditions resembling those of the natural site of infection and that Spf adhesin plays an important role in the adherence of sorbitol-fermenting strains.

\subsection{ToxB and Efa1 adhesins}

\subsubsection{Description}

In 2000, Nicholls et al. [78] identified a locus required for the adherence in vitro of an EHEC strain of serogroup O111:H- by transposon mutagenesis. This factor was called Efa1 for "EHEC Factor for Adherence". The efal locus has a size of $9669 \mathrm{bp}$ and is situated on the pathogenicity island $\mathrm{O} 122$ [53]. The efal locus is strongly associated with nonO157 EHEC and EPEC strains and a truncated variant of $1299 \mathrm{pb}$ is present in O157 EHEC strains [4, 44, 84]. Efa1 has 97.4\% homology in amino acid and $99.9 \%$ identity in nucleic sequence with Lymphocyte Inhibitory FactorA (LifA), described in EPEC strain E2348/69, which codes for the lymphostatin. This toxin inhibits the proliferation of lymphocytes and the production of interleukin 2 and 4 [54].

In 2001, Tatsuno et al. [107] identified toxB on the pO157 plasmid in Sakai O157 EHEC strain. The toxB locus is $9.5 \mathrm{~kb}$ long and shares homology with the efal locus (28\% of nucleic acid sequence and $47 \%$ of amino acid sequence) and the gene coding for the toxin B from Clostridium difficile $(20 \%$ of similarities in amino-acid sequence). Tozzoli et al. [118] looked for the presence of the entire tox $B$ sequence in EHEC and EPEC strains of several serogroups by PCR and hybridisation. The complete toxB sequence is present in all $\mathrm{O} 157$ EHEC strains, in about $50 \%$ of EHEC O26 
strains, in a few EHEC O118 and O123 strains and in a few EPEC O26 and O86 strains but not in $\mathrm{O} 111$ and $\mathrm{O} 103$ strains. They also suggested the existence of a polymorphism of tox $B$ genes among the different $E$. coli serogroups. Finally, Tatarczak et al. [106] detected the toxB gene in VTEC strains from humans and cattle.

\subsubsection{Involvement in the adherence}

The mutant deleted in Efal is deficient in adherence on CHO (Chinese Hamster Ovary) cells. Shedding studies on calves aged 4 to 11 days with wild type and mutant strains show that the colonisation of the intestine is influenced by Efa1 for O5 and O111 EHEC strains [101]. In spite of the high homology between lifA and efal, mutants deleted in lifA produce the $\mathrm{A} / \mathrm{E}$ lesion and LA.

ToxB contributes to the adherence by the stimulation of the production of EspA, EspB (two translocator proteins) and translocated intimin receptor (Tir). Indeed, a pO157-cured strain of O157 Sakai has its adherence decreased and the expression level of the effectors EspA, EspB and Tir in this strain also decreased. The adherence is restored with the complementation of the pO157-cured strain of O157Sakai with a mini-pO157 plasmid composed of the tox $B$ and ori regions. Stevens et al. [102] have shown that ToxB influences the expression of the LEE but not intestinal colonisation in sheep and calves in contrast with Tir.

Regarding the prevalence results [4], both genes are present in the majority of the EHEC and EPEC strains and are mostly absent in non pathogenic $E$. coli strains. Therefore, they might play an important role in the adherence of EPEC and EHEC strains.

\subsection{Long polar fimbriae}

\subsubsection{Description}

Long polar fimbria (LPF) was first described in Salmonella enterica serovar Typhimurium [6]. Then five homologues were described in $E$. coli strains. Two variants were found in O157 EHEC strains: lpfA1 (localised in pathogenicity island OI141) and lpfA2 (localised in pathogenicity island OI154). Doughty et al.
[32] identified an lpf homologue in O113:H21 VTEC strain (called $\operatorname{lp} f A_{O 113}$ ) localised in pathogenicity island OI154. Toma et al. [112] identified another variant in O26:H11 EHEC strain (called $l p f A_{O 26}$ ) localised in pathogenicity island OI141. Finally, Tatsuno et al. [108] identified an lpf homologue in EPEC strain E2348/ 69; however, this Lpf adhesin does not appear to be implicated in the adherence in this strain. Toma et al. [113] studied the distribution of

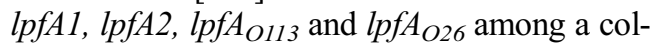
lection of $E$. coli strains. lpfA1 and $\operatorname{lpfA2}$ are found in most O157 EHEC strains and O145 EHEC strains and in a few EPEC and ETEC strains $[112,113] . l p f A_{O 113}$ and $l p f A_{O 26}$ are found in strains of different serogroups and pathotypes (VTEC, EPEC, EHEC, EAEC, ETEC) [4].

\subsubsection{Involvement in the adherence}

Baumler et al. [6] have shown that Lpf facilitates the attachment of the bacteria to murine Peyer patch cells. Torres et al. demonstrated that the adherence to HeLa cells decreases when lpfAI and $\operatorname{lpf} A 2$ are mutated $[115,117]$. LpfA $\mathrm{O} 113$ enhances the adherence of O113:H21 VTEC strains on CHO-K1 cells [32]. The LPF is present in a wide range of strains isolated from different sources and belonging to different seropathotypes. Toma et al. [113] suggested that the acquisition of these genes in specific lineage of $E$. coli has probably contributed to the emergence of a pathogen from a typically commensal organism.

\subsection{F9 fimbrial adhesin}

\subsubsection{Description}

A novel potential fimbrial operon called F9 has been identified by transposon mutagenesis with $\mathrm{O} 26$ and $\mathrm{O} 157$ strains [34, 121]. This operon is present in most EHEC strains in all serogroups.

\subsubsection{Involvement in the adherence}

It has been shown that F9 promotes colonisation in vivo in calves. When complemented in $\mathrm{K} 12$, the binding of the bacteria is increased in bovine epithelial cells. However, the complementation of an $\mathrm{O} 157$ strain reduces the 
adherence. This phenomenon is probably due to a physical competition with the type III secretion system present in $\mathrm{O} 157$ strains. A deletion of the operon in $\mathrm{O} 157$ strains reduces the shedding of the bacteria but the colonisation of the rectum is still present. Low et al. [64] concluded that F9 is not responsible for the rectal tropism of O157 strains but that it may be involved in the colonisation of other intestinal sites.

\subsection{Paa adhesin}

\subsubsection{Description}

Paa (Porcine attaching- and effacing associated) adhesin was first identified in a porcine EPEC strain (PEPEC) by transposon mutagenesis $[2,5]$. The paa gene of $753 \mathrm{pb}$ encodes a $27.6 \mathrm{kDa}$ protein and is localised on the chromosome. Studies of the distribution in enteric $E$. coli strains have revealed that paa is present, on the one hand, in EHEC O157:H7 and O26, and in dog, rabbit, and pig EPEC isolates, and to a lesser extent in human EPEC strains and, on the other hand, in ETEC strains. In 2007, Leclerc et al. [60] studied paa in O149 ETEC strains. paa in ETEC is carried by high molecular weight plasmids and all paa-positive strains possess est $B$, elt, ast $A$ and fae $G$ genes (coding respectively for the heat-stable enterotoxin $\mathrm{B}$, the heat-labile enterotoxin, the enteroaggregative heat-stable enterotoxin and a part of F4 operon) and more than half also carry the estA gene (coding for heat-stable enterotoxin A). Moreover, they suggested that paa from ETEC and EPEC/EHEC strains could be derived from a common ancestor because paa from ETEC strains and paa from EPEC/EHEC strains contain IS signatures.

\subsubsection{Involvement in the adherence}

The transposon mutagenesis performed by An et al. [2] suggested that Paa plays a role in the $\mathrm{A} / \mathrm{E}$ mechanism. Indeed, no $\mathrm{A} / \mathrm{E}$ lesions were induced using a mutant deficient in the paa gene and the adherence phenotype was restored after the complementation of the paa mutant [5]. In addition, anti-Paa antibodies reduce the proportion of intact villi showing intimate adherence. In vivo, eae-positive and paa-negative mutants induce less severe or no $\mathrm{A} / \mathrm{E}$ lesions in piglets that in the end developed no diarrhoea or delayed-onset diarrhoea.

\subsection{Iha adhesin}

\subsubsection{Description}

Tarr et al. [105] described an outer membrane protein similar to Iron-Regulated Gene A (IrgA) from Vibrio cholerae in cosmid obtained from the O157:H7 strain. This protein was called Iha for "IrgA Homologue Adhesin". This protein is $67 \mathrm{kDa}$ in the $\mathrm{O} 157: \mathrm{H} 7$ strain and $78 \mathrm{kDa}$ in laboratory E. coli. The iha gene is found in EPEC, EHEC and VTEC strains from humans, cattle and pigs [4, 104, 106, 112]. The iha gene is also present in $39 \%$ of E. coli isolated from patients with urosepsis [51] and it has been shown to be a virulence factor in urinary tract infection-associated strains (UTI) [52].

\subsubsection{Involvement in the adherence}

The adherence of mutants deleted in iha on eukaryotic cells is decreased and the iha gene provides an adherence of K12 strains to HeLa and MDBK cells [105]. Rashid et al. [89] and Leveillé et al. [62] showed that the transcription of iha is repressed by iron with a direct interaction between Ferric Uptake Regulation protein (Fur) and Tha. Moreover, Iha represents a Furregulated catecholate siderophore receptor in UTI strains. Therefore, Iha may be a dual-function virulence factor: the adherence to the host cell and the siderophore receptor activity.

\subsection{AIDA adhesin}

\subsubsection{Description}

Benz et al. [7-10] studied an O126:H27 EPEC strain implicated in infantile diarrhoea and presenting a DA phenotype. They showed that this DA phenotype is mediated by a $6 \mathrm{~kb}$ DNA fragment present in a $100 \mathrm{~kb}$ plasmid. This $6 \mathrm{~kb}$ fragment codes for an adhesin, called AIDA-I. The aida-I locus is composed of two 
genes (1) aah an autotransporter adhesin heptosyltransferase encoding AAH protein, which modifies AIDA-I adhesin, and (2) aidA, the AIDA, consisting of AIDA-I (orfB) and AIDAc (orfBc). In 2001, Niewerth et al. [79] detected the aida-I locus in a porcine VTEC strain involved in oedema disease. The aida-I locus is localised on the same plasmid as the gene coding for the F18 adhesin in porcine strains [69]. In 2007, Zhao et al. [130] showed that the aida- $I$ locus is occasionally present in porcine strains involved in post weaning diarrhoea and that a transfer between human and porcine strains is possible.

\subsubsection{Involvement in the adherence}

AIDA-I is involved in the DA phenotype but is also involved in bacteria aggregation and in biofilm formation [90, 97]. There is an intercellular interaction between AIDA-I-AIDA-I but also AIDA-I-Antigen43 (an autotransporter protein), which lead to the aggregation of cells. Several studies have focussed on the receptor of the AIDA-I adhesin. Laarmann et al. [59] found that AIDA-I recognises an integral membrane glycoprotein in HeLa cells as receptor of $119 \mathrm{kDa}$ called gp119. Fang et al. [36] hypothesised the existence of a receptor in porcine intestinal mucus and found two proteins of 65 and $120 \mathrm{kDa}$ (p65 and p120), that bind with high affinity to purified AIDA-I adhesion. In addition, aida-I positive $E$. coli binds to these proteins with higher affinity than do aida-I negative mutants. Recently, Benz et al. [11] showed that the environmental factors (different growth conditions) and the genetic backgrounds of the strain significantly influence the transcription activity of the genes.

\subsection{Other non-specific miscellaneous adhesins}

With the sequencing of the $\mathrm{O} 157$ strain [44, 84], several fimbriae were identified in silico. Low et al. [65] studied the distribution of $16 \mathrm{fi}-$ mbrial gene clusters in E. coli and the expression of these fimbriae in different conditions. In those 16 identified fimbriae, 4 are specific to $\mathrm{O} 157$ strains in comparison with the K12 strain and 4 fimbriae correspond to previously studied adhesins (LpfA1, LpfA2, Curli and Type 1 fimbriae).

Calcium binding Antigen 43 Homologue (Cah) is a protein described in the $\mathrm{O} 157$ strain and is homologous to antigen 43 and AIDA-I [116]. This gene is $2850 \mathrm{pb}$ long and is present in duplicate in O157 strain EDL933. A K12 strain complemented with cah produces two proteins (one outer membrane protein and one heat extract protein) and shows the capacity to autoaggregate. In O157, Cah protein participates in biofilm formation and also binds to calcium. This protein is implicated more in autoaggregation properties than in binding to eukaryotic cells.

Recently, several other adherence factors have been described. First, Xicohtencatl-Cortes et al. described the Haemorrhagic Coli Pilus (HCP). HCP is found in EHEC and EPEC strains [4]. The inactivation of the main subunit (hcpA gene) in 0157:H7 EHEC reduces adherence to cultured human intestinal and bovine renal epithelial cells and to porcine and bovine gut explants [127]. They also found that in addition to promoting bacterial attachment to host cells, HCP also plays a role in the invasion of epithelial cells, in the haemagglutination of rabbit erythrocytes, in biofilm formation, in the specific binding to laminin and fibronectin of the host cells, and in twitching motility [128]. Then, in 2008, Wells et al. [125] described a novel autotransporter protein, called EhaA (EHEC autotransporter) implicated in adherence and biofilm formation in the O157:H7 strain. Finally, Ferreira et al. [37] described the implication of the pst operon (the phosphate-specific transport system) on the adherence to host cells in an EPEC strain. Indeed, in the absence of pst there is a decrease in the expression of the main EPEC adhesins and a reduction in bacterial adherence to epithelial cells in vitro.

\section{CONCLUDING REMARKS}

Considering that adherence is the basis of host specificity for a lot of pathogens and that ruminants (especially cattle) are considered to represent the main reservoir of EHEC and 
VTEC strains for humans, we could wonder about the distribution of the EPEC, EHEC and VTEC adhesins among humans and animals. Based on different prevalence studies, we can affirm that, except for a few adhesins (Bfp, REPEC and F18 adhesins), EPEC, EHEC and VTEC adhesins do not seem to be host specific. There are several possible explanations. First, the host specificity is based on other factors. This host specificity may be based upon another adhesin not yet discovered or another property such as the following: (i) differences in the sequences of genes coding for some adhesins present in human and bovine strains, resulting in host and tissue tropism, as already described in other families of fimbrial ( $\mathrm{P}$ family) or afimbrial (AFA family) adhesins $[12,35]$; (ii) variation in the expression of some adhesin-encoding genes according to the growth environment (bovine or human intestines; intestinal segments; age of the host; etc.), as observed for other genes [29]; and/or (iii) properties other than adherence such as an intermediate metabolism, which allows the bacteria to be better adapted to a bovine intestinal environment, such as the young calf intestine $[34,121]$. Second, there is no actual host specificity and the strains carrying specific adhesins (Bfp, REPEC and F18 adhesins) could represent a subgroup of strains specifically adapted to one host and/or one environment. Therefore, the other EPEC, EHEC and VTEC strains could be considered as only one group that carry several adhesins without any specificity and acting together with the aim to attach the bacteria to the host cells. Thus, it is not surprising that the bacteria could have different adhesin profiles that are not linked to one specific host or to one specific pathotype.

Acknowledgements. Marjorie Bardiau is a $\mathrm{PhD}$ fellow of the "Fonds pour la formation à la Recherche dans l'Industrie et dans 1'Agriculture" (FRIA) and her research is supported by a Grant from the "Service Public Fédéral Santé publique, sécurité de la chaîne alimentaire et environnement: Division Recherche contractuelle", contract S-6172, and in part by the European Network of Excellence EADGENE (European Animal Disease Genomics Network of Excellence for Animal Health and Food Safety).

\section{REFERENCES}

[1] Adams L.M., Simmons C.P., Rezmann L., Strugnell R.A., Robins-Browne R.M., Identification and characterization of a K88- and CS31A-like operon of a rabbit enteropathogenic Escherichia coli strain which encodes fimbriae involved in the colonization of rabbit intestine, Infect. Immun. (1997) 65:5222-5230.

[2] An H., Fairbrother J.M., Desautels C., Harel J., Distribution of a novel locus called Paa (porcine attaching and effacing associated) among enteric Escherichia coli, Adv. Exp. Med. Biol. (1999) 473:179-184.

[3] Baldini M.M., Kaper J.B., Levine M.M., Candy D.C., Moon H.W., Plasmid-mediated adhesion in enteropathogenic Escherichia coli, J. Pediatr. Gastroenterol. Nutr. (1983) 2:534-538

[4] Bardiau M., Labrozzo S., Mainil J.G., Putative adhesins of enteropathogenic and enterohemorrhagic Escherichia coli of serogroup O26 isolated from humans and cattle, J. Clin. Microbiol. (2009) 47:2090-2096.

[5] Batisson I., Guimond M.P., Girard F., An H., Zhu C., Oswald E., et al., Characterization of the novel factor paa involved in the early steps of the adhesion mechanism of attaching and effacing Escherichia coli, Infect. Immun. (2003) 71:4516-4525.

[6] Baumler A.J., Tsolis R.M., Heffron F., The lpf fimbrial operon mediates adhesion of Salmonella typhimurium to murine Peyer's patches, Proc. Natl. Acad. Sci. USA (1996) 93:279-283.

[7] Benz I., Schmidt M.A., Cloning and expression of an adhesin (AIDA-I) involved in diffuse adherence of enteropathogenic Escherichia coli, Infect. Immun. (1989) 57:1506-1511.

[8] Benz I., Schmidt M.A., AIDA-I, the adhesin involved in diffuse adherence of the diarrhoeagenic Escherichia coli strain 2787 (O126:H27), is synthesized via a precursor molecule, Mol. Microbiol. (1992) 6:1539-1546.

[9] Benz I., Schmidt M.A., Isolation and serologic characterization of AIDA-I, the adhesin mediating the diffuse adherence phenotype of the diarrhea-associated Escherichia coli strain 2787 (O126:H27), Infect. Immun. (1992) 60:13-18.

[10] Benz I., Schmidt M.A., Diffuse adherence of enteropathogenic Escherichia coli strains - processing of AIDA-I, Zentralbl. Bakteriol. (1993) 278:197-208.

[11] Benz I., van Alen T., Bolte J., Wormann M.E., Schmidt M.A., Modulation of transcription and characterization of the promoter organization of the autotransporter adhesin heptosyltransferase and the autotransporter adhesin AIDA-I, Microbiology (2010) 156:1155-1166.

[12] Berendson R., Cheney C.P., Schad P.A., Boedeker E.C., Species-specific binding of purified pili (AF/R1) from the Escherichia coli RDEC-1 to rabbit intestinal mucosa, Gastroenterology (1983) 85:837-845.

[13] Bertschinger H.U., Bachmann M., Mettler C., Pospischil A., Schraner E.M., Stamm M., et al., Adhesive 
fimbriae produced in vivo by Escherichia coli O139:K12(B):H1 associated with enterotoxaemia in pigs, Vet. Microbiol. (1990) 25:267-281.

[14] Bertschinger H.U., Stamm M., Vogeli P., Inheritance of resistance to oedema disease in the pig: experiments with an Escherichia coli strain expressing fimbriae 107, Vet. Microbiol. (1993) 35:79-89.

[15] Bertschinger H.U., Nief V., Tschape H., Active oral immunization of suckling piglets to prevent colonization after weaning by enterotoxigenic Escherichia coli with fimbriae F18, Vet. Microbiol. (2000) 71:255-267.

[16] Bielaszewska M., Prager R., Vandivinit L., Musken A., Mellmann A., Holt N.J., et al., Detection and characterization of the fimbrial sfp cluster in enterohemorrhagic Escherichia coli $\mathrm{O} 165: \mathrm{H} 25 / \mathrm{NM}$ isolates from humans and cattle, Appl. Environ. Microbiol. (2009) 75:64-71.

[17] Blanco J.E., Blanco M., Blanco J., Mora A., Balaguer L., Mourino M., et al., O serogroups, biotypes, and eae genes in Escherichia coli strains isolated from diarrheic and healthy rabbits, J. Clin. Microbiol. (1996) 34:3101-3107.

[18] Blanco M., Padola N.L., Kruger A., Sanz M.E., Blanco J.E., Gonzalez E.A., et al., Virulence genes and intimin types of Shiga-toxin-producing Escherichia coli isolated from cattle and beef products in Argentina, Int. Microbiol. (2004) 7:269-276.

[19] Brooks J.T., Sowers E.G., Wells J.G., Greene K.D., Griffin P.M., Hoekstra R.M., Strockbine N.A., Non-O157 Shiga toxin-producing Escherichia coli infections in the United States, 1983-2002, J. Infect. Dis. (2005) 192:1422-1429.

[20] Brunder W., Khan A.S., Hacker J., Karch H., Novel type of fimbriae encoded by the large plasmid of sorbitolfermenting enterohemorrhagic Escherichia coli O157: H(-), Infect. Immun. (2001) 69:4447-4457.

[21] Buvens G., Pierard D., Hachimi-Idrissi S., Lauwers S., First sorbitol-fermenting Verocytotoxin-producing Escherichia coli O157: H- isolated in Belgium, Acta Clin. Belg. (2009) 64:59-64.

[22] Cantey J.R., Blake R.K., Williford J.R., Moseley S.L., Characterization of the Escherichia coli AF/R1 pilus operon: novel genes necessary for transcriptional regulation and for pilus-mediated adherence, Infect. Immun. (1999) 67:2292-2298.

[23] Caprioli A., Morabito S., Brugëre H., Oswald E., Enterohaemorrhagic Escherichia coli: emerging issues on virulence and modes of transmission, Vet. Res. (2005) 36:289-311.

[24] Cergole-Novella M.C., Nishimura L.S., Dos Santos L.F., Irino K., Vaz T.M., Bergamini A.M., Guth B.E., Distribution of virulence profiles related to new toxins and putative adhesins in Shiga toxin-producing Escherichia coli isolated from diverse sources in Brazil, FEMS Microbiol. Lett. (2007) 274:329-334.
[25] Chen H.D., Frankel G., Enteropathogenic Escherichia coli: unravelling pathogenesis, FEMS Microbiol. Rev. (2005) 29:83-98.

[26] Cheng D., Sun H., Xu J., Gao S., Prevalence of fimbial colonization factors F18ab and F18ac in Escherichia coli isolates from weaned piglets with edema and/or diarrhea in China, Vet. Microbiol. (2005) 110:35-39.

[27] Coddens A., Verdonck F., Tiels P., Rasschaert K., Goddeeris B.M., Cox E., The age-dependent expression of the F18 + E. coli receptor on porcine gut epithelial cells is positively correlated with the presence of histo-blood group antigens, Vet. Microbiol. (2007) 122:332-341.

[28] Daniel A., Singh A., Crowther L.J., Fernandes P.J., Schreiber W., Donnenberg M.S., Interaction and localization studies of enteropathogenic Escherichia coli type IV bundle-forming pilus outer membrane components, Microbiology (2006) 152:2405-2420.

[29] De Sablet T., Chassard C., Bernalier-Donadille A., Vareille M., Gobert A.P., Martin C., Human microbiotasecreted factors inhibit shiga toxin synthesis by enterohemorrhagic Escherichia coli O157:H7, Infect. Immun. (2009) 77:783-790.

[30] Donnenberg M.S., Giron J.A., Nataro J.P., Kaper J.B., A plasmid-encoded type IV fimbrial gene of enteropathogenic Escherichia coli associated with localized adherence, Mol. Microbiol. (1992) 6:3427-3437.

[31] Donnenberg M.S., Kaper J.B., Enteropathogenic Escherichia coli, Infect. Immun. (1992) 60:3953-3961.

[32] Doughty S., Sloan J., Bennett-Wood V., Robertson M., Robins-Browne R.M., Hartland E.L., Identification of a novel fimbrial gene cluster related to long polar fimbriae in locus of enterocyte effacementnegative strains of enterohemorrhagic Escherichia coli, Infect. Immun. (2002) 70:6761-6769.

[33] Dow M.A., Toth I., Alexa P., Davies M., Malik A., Oswald E., Nagy B., Predominance of afr2 and ral fimbrial genes related to those encoding the K88 and CS31A fimbrial adhesins in enteropathogenic Escherichia coli isolates from rabbits with postweaning diarrhea in Central Europe, J. Clin. Microbiol. (2005) 43:1366-1371.

[34] Dziva F., van Diemen P.M., Stevens M.P., Smith A.J., Wallis T.S., Identification of Escherichia coli O157: $\mathrm{H} 7$ genes influencing colonization of the bovine gastrointestinal tract using signature-tagged mutagenesis, Microbiology (2004) 150:3631-3645.

[35] Fairbrother J.M., Nadeau E., Gyles C.L., Escherichia coli in postweaning diarrhea in pigs: an update on bacterial types, pathogenesis, and prevention strategies, Anim. Health Res. Rev. (2005) 6: 17-39.

[36] Fang Y., Ngeleka M., Middleton D.M., Simko E., Isolation and identification of AIDA-I receptors in porcine intestinal mucus, Vet. Microbiol. (2008) 126:345-355.

[37] Ferreira G.M., Spira B., The pst operon of enteropathogenic Escherichia coli enhances bacterial adherence to epithelial cells, Microbiology (2008) 154:2025-2036. 
[38] Fiederling F., Boury M., Petit C., Milon A., Adhesive factor/rabbit 2, a new fimbrial adhesin and a virulence factor from Escherichia coli O103, a serogroup enteropathogenic for rabbits, Infect. Immun. (1997) 65:847-851.

[39] Friedrich A.W., Nierhoff K.V., Bielaszewska M., Mellmann A., Karch H., Phylogeny, clinical associations, and diagnostic utility of the pilin subunit gene $(\operatorname{sfpA})$ of sorbitol-fermenting, enterohemorrhagic Escherichia coli O157:H, J. Clin. Microbiol. (2004) 42:4697-4701.

[40] Frydendahl K., Kare Jensen T., Strodl Andersen J., Fredholm M., Evans G., Association between the porcine Escherichia coli F18 receptor genotype and phenotype and susceptibility to colonisation and postweaning diarrhoea caused by E. coli O138:F18, Vet. Microbiol. (2003) 93:39-51.

[41] Giron J.A., Ho A.S., Schoolnik G.K., An inducible bundle-forming pilus of enteropathogenic Escherichia coli, Science (1991) 254:710-713.

[42] Goffaux F., China B., Janssen L., Mainil J., Genotypic characterization of enteropathogenic Escherichia coli (EPEC) isolated in Belgium from dogs and cats, Res. Microbiol. (2000) 151:865-871.

[43] Hansson G.C., Structural aspects of blood group glycosphingolipids in the gastrointestinal tract, Adv. Exp. Med. Biol. (1988) 228:465-494.

[44] Hayashi T., Makino K., Ohnishi M., Kurokawa K., Ishii K., Yokoyama K., et al., Complete genome sequence of enterohemorrhagic Escherichia coli O157:H7 and genomic comparison with a laboratory strain K-12, DNA Res. (2001) 8:11-22.

[45] Hernandes R.T., Elias W.P., Vieira M.A., Gomes T.A., An overview of atypical enteropathogenic Escherichia coli, FEMS Microbiol. Lett. (2009) 297:137-149.

[46] Hornitzky M.A., Mercieca K., Bettelheim K.A., Djordjevic S.P., Bovine feces from animals with gastrointestinal infections are a source of serologically diverse atypical enteropathogenic Escherichia coli and Shiga toxin-producing $E$. coli strains that commonly possess intimin, Appl. Environ. Microbiol. (2005) 71:3405-3412.

[47] Imberechts H., De Greve H., Schlicker C., Bouchet H., Pohl P., Charlier G., et al., Characterization of F107 fimbriae of Escherichia coli 107/86, which causes edema disease in pigs, and nucleotide sequence of the F107 major fimbrial subunit gene, fedA, Infect. Immun. (1992) 60:1963-1971.

[48] Imberechts H., Wild P., Charlier G., De Greve H., Lintermans P., Pohl P., Characterization of F18 fimbrial genes fedE and fedF involved in adhesion and length of enterotoxemic Escherichia coli strain 107/86, Microb. Pathog. (1996) 21:183-192.

[49] Jakubczak A., Szych J., Januszkiewicz K., Characterization of first sorbitol-fermenting shiga toxin-producing Escherichia coli O157:H- strain isolated in Poland, Med. Dosw. Mikrobiol. (2008) 60:173-181 (in Polish).

[50] Jenkins C., Perry N.T., Cheasty T., Shaw D.J., Frankel G., Dougan G., et al., Distribution of the saa gene in strains of Shiga toxin-producing Escherichia coli of human and bovine origins, J. Clin. Microbiol. (2003) 41:1775-1778.

[51] Johnson J.R., Russo T.A., Tarr P.I., Carlino U., Bilge S.S., Vary J.C. Jr, Stell A.L., Molecular epidemiological and phylogenetic associations of two novel putative virulence genes, iha and iroN (E. coli), among Escherichia coli isolates from patients with urosepsis, Infect. Immun. (2000) 68:3040-3047.

[52] Johnson J.R., Jelacic S., Schoening L.M., Clabots C., Shaikh N., Mobley H.L., Tarr P.I., The IrgA homologue adhesin Iha is an Escherichia coli virulence factor in murine urinary tract infection, Infect. Immun. (2005) 73:965-971.

[53] Karmali M.A., Mascarenhas M., Shen S., Ziebell K., Johnson S., Reid-Smith R., et al., Association of genomic $\mathrm{O}$ island 122 of Escherichia coli EDL 933 with verocytotoxin-producing Escherichia coli seropathotypes that are linked to epidemic and/or serious disease, J. Clin. Microbiol. (2003) 41:4930-4940.

[54] Klapproth J.M., Scaletsky I.C., McNamara B.P., Lai L.C., Malstrom C., James S.P., Donnenberg M.S., A large toxin from pathogenic Escherichia coli strains that inhibits lymphocyte activation, Infect. Immun. (2000) 68:21482155 .

[55] Kobayashi K., Seto K., Yatsuyanagi J., Saito S., Terao M., Kaneko M., et al., Presence of the genes regarding adherence factors of Escherichia coli isolates and a consideration of the procedure for detection of diarrheagenic strain, Kansenshogaku Zasshi (2002) 76:911-920 (in Japanese).

[56] Konowalchuk J., Speirs J.I., Stavric S., Vero response to a cytotoxin of Escherichia coli, Infect. Immun. (1977) 18:775-779.

[57] Krause G., Zimmermann S., Beutin L., Investigation of domestic animals and pets as a reservoir for intimin(eae) gene positive Escherichia coli types, Vet. Microbiol. (2005) 106:87-95

[58] Krejany E.O., Grant T.H., Bennett-Wood V., Adams L.M., Robins-Browne R.M., Contribution of plasmidencoded fimbriae and intimin to capacity of rabbit-specific enteropathogenic Escherichia coli to attach to and colonize rabbit intestine, Infect. Immun. (2000) 68:64726477.

[59] Laarmann S., Schmidt M.A., The Escherichia coli AIDA autotransporter adhesin recognizes an integral membrane glycoprotein as receptor, Microbiology (2003) 149:1871-1882.

[60] Leclerc S., Boerlin P., Gyles C., Dubreuil J.D., Mourez M., Fairbrother J.M., Harel J., paa, originally identified in attaching and effacing Escherichia coli, is also associated with enterotoxigenic E. coli, Res. Microbiol. (2007) 158:97-104.

[61] Lee J.H., Choi S.J., Isolation and characteristics of sorbitol-fermenting Escherichia coli O157 strains from cattle, Microbes Infect. (2006) 8:2021-2026. 
[62] Leveille S., Caza M., Johnson J.R., Clabots C., Sabri M., Dozois C.M., Iha from an Escherichia coli urinary tract infection outbreak clonal group A strain is expressed in vivo in the mouse urinary tract and functions as a catecholate siderophore receptor, Infect. Immun. (2006) 74:3427-3436.

[63] Levine M.M., Nataro J.P., Karch H., Baldini M.M., Kaper J.B., Black R.E., et al., The diarrheal response of humans to some classic serotypes of enteropathogenic Escherichia coli is dependent on a plasmid encoding an enteroadhesiveness factor, J. Infect. Dis. (1985) 152:550 559 .

[64] Low A.S., Dziva F., Torres A.G., Martinez J.L., Rosser T., Naylor S., et al., Cloning, expression, and characterization of fimbrial operon F9 from enterohemorrhagic Escherichia coli O157:H7, Infect. Immun. (2006) $74: 2233-2244$

[65] Low A.S., Holden N., Rosser T., Roe A.J., Constantinidou C., Hobman J.L., et al., Analysis of fimbrial gene clusters and their expression in enterohaemorrhagic Escherichia coli O157:H7, Environ. Microbiol. (2006) 8:1033-1047.

[66] Lu Y., Iyoda S., Satou H., Itoh K., Saitoh T., Watanabe H., A new immunoglobulin-binding protein, EibG, is responsible for the chain-like adhesion phenotype of locus of enterocyte effacement-negative, shiga toxinproducing Escherichia coli, Infect. Immun. (2006) 74:5747-5755

[67] Lucchesi P.M., Kruger A., Parma A.E., Distribution of saa gene variants in verocytotoxigenic Escherichia coli isolated from cattle and food, Res. Microbiol. (2006) 157:263-266

[68] Mainil J., Shiga/verocytotoxins and Shiga/verotoxigenic Escherichia coli in animals, Vet. Res. (1999) 30:235-257.

[69] Mainil J.G., Jacquemin E., Pohl P., Kaeckenbeeck A., Benz I., DNA sequences coding for the F18 fimbriae and AIDA adhesin are localised on the same plasmid in Escherichia coli isolates from piglets, Vet. Microbiol. (2002) 86:303-311.

[70] Mainil J.G., Daube G., Verotoxigenic Escherichia coli from animals, humans and foods: who's who?, J. Appl. Microbiol. (2005) 98:1332-1344.

[71] Moon H.W., Whipp S.C., Argenzio R.A., Levine M.M., Giannella R.A., Attaching and effacing activities of rabbit and human enteropathogenic Escherichia coli in pig and rabbit intestines, Infect. Immun. (1983) 41:13401351.

[72] Moreira C.G., Palmer K., Whiteley M., Sircili M.P., Trabulsi L.R., Castro A.F., Sperandio V., Bundle-forming pili and EspA are involved in biofilm formation by enteropathogenic Escherichia coli, J. Bacteriol. (2006) 188:3952-3961.

[73] Moxley R.A., Francis D.H., Natural and experimental infection with an attaching and effacing strain of Escherichia coli in calves, Infect. Immun. (1986) 53:339-346.
[74] Moxley R.A., Edema disease, Vet. Clin. North Am. Food Anim. Pract. (2000) 16:175-185.

[75] Musken A., Bielaszewska M., Greune L., Schweppe C.H., Muthing J., Schmidt H., et al., Anaerobic conditions promote expression of Sfp fimbriae and adherence of sorbitol-fermenting enterohemorrhagic Escherichia coli O157:NM to human intestinal epithelial cells, Appl. Environ. Microbiol. (2008) 74:1087-1093.

[76] Nagy B., Casey T.A., Moon H.W., Phenotype and genotype of Escherichia coli isolated from pigs with postweaning diarrhea in Hungary, J. Clin. Microbiol. (1990) 28:651-653.

[77] Nataro J.P., Kaper J.B., Diarrheagenic Escherichia coli, Clin. Microbiol. Rev. (1998) 11:142-201.

[78] Nicholls L., Grant T.H., Robins-Browne R.M., Identification of a novel genetic locus that is required for in vitro adhesion of a clinical isolate of enterohaemorrhagic Escherichia coli to epithelial cells, Mol. Microbiol. (2000) 35:275-288.

[79] Niewerth U., Frey A., Voss T., Le Bouguenec C., Baljer G., Franke S., Schmidt M.A., The AIDA autotransporter system is associated with F18 and stx2e in Escherichia coli isolates from pigs diagnosed with edema disease and postweaning diarrhea, Clin. Diagn. Lab. Immunol. (2001) 8:143-149.

[80] Orden J.A., Cortes C., Ruiz-Santa-quiteria J.A., Martinez S., de la Fuente R., Detection of the saa gene in verotoxin-producing Escherichia coli from ruminants, J. Vet. Diagn. Invest. (2005) 17:65-67.

[81] Osek J., Prevalence of virulence factors of Escherichia coli strains isolated from diarrheic and healthy piglets after weaning, Vet. Microbiol. (1999) 68:209-217.

[82] Paton A.W., Srimanote P., Woodrow M.C., Paton J.C., Characterization of Saa, a novel autoagglutinating adhesin produced by locus of enterocyte effacementnegative Shiga-toxigenic Escherichia coli strains that are virulent for humans, Infect. Immun. (2001) 69:69997009 .

[83] Penteado A.S., Ugrinovich L.A., Blanco J., Blanco M., Blanco J.E., Mora A., et al., Serobiotypes and virulence genes of Escherichia coli strains isolated from diarrheic and healthy rabbits in Brazil, Vet. Microbiol. (2002) 89:41-51

[84] Perna N.T., Plunkett G. 3rd, Burland V., Mau B., Glasner J.D., Rose D.J., et al., Genome sequence of enterohaemorrhagic Escherichia coli O157:H7, Nature (2001) 409:529-533.

[85] Pillien F., Chalareng C., Boury M., Tasca C., de Rycke J., Milon A., Role of Adhesive Factor/Rabbit 2 in experimental enteropathogenic Escherichia coli O103 diarrhea of weaned rabbit, Vet. Microbiol. (1996) 50:105-115.

[86] Puente J.L., Bieber D., Ramer S.W., Murray W., Schoolnik G.K., The bundle-forming pili of enteropathogenic Escherichia coli: transcriptional regulation by environmental signals, Mol. Microbiol. (1996) 20:87-100. 
[87] Rafiee P., Leffler H., Byrd J.C., Cassels F.J., Boedeker E.C., Kim Y.S., A sialoglycoprotein complex linked to the microvillus cytoskeleton acts as a receptor for pilus (AF/R1) mediated adhesion of enteropathogenic Escherichia coli (RDEC-1) in rabbit small intestine, J. Cell Biol. (1991) 115:1021-1029.

[88] Rangel J.M., Sparling P.H., Crowe C., Griffin P.M., Swerdlow D.L., Epidemiology of Escherichia coli O157:H7 outbreaks, United States, 1982-2002, Emerg. Infect. Dis. (2005) 11:603-609.

[89] Rashid R.A., Tarr P.I., Moseley S.L., Expression of the Escherichia coli IrgA homolog adhesin is regulated by the ferric uptake regulation protein, Microb. Pathog. (2006) 41:207-217.

[90] Ravi M., Ngeleka M., Kim S.H., Gyles C., Berthiaume F., Mourez M., et al., Contribution of AIDA-I to the pathogenicity of a porcine diarrheagenic Escherichia coli and to intestinal colonization through biofilm formation in pigs, Vet. Microbiol. (2007) 120:308-319.

[91] Rippinger P., Bertschinger H.U., Imberechts H., Nagy B., Sorg I., Stamm M., et al., Designations F18ab and F18ac for the related fimbrial types F107, 2134P and 8813 of Escherichia coli isolated from porcine postweaning diarrhoea and from oedema disease, Vet. Microbiol. (1995) 45:281-295.

[92] Robins-Browne R.M., Traditional enteropathogenic Escherichia coli of infantile diarrhea, Rev. Infect. Dis. (1987) 9:28-53.

[93] Rowe P.C., Orrbine E., Lior H., Wells G.A., McLaine P.N., Diarrhoea in close contacts as a risk factor for childhood haemolytic uraemic syndrome. The CPKDRC co-investigators, Epidemiol. Infect. (1993) 110:9-16.

[94] Ryu H., Kim Y.S., Grange P.A., Cassels F.J., Escherichia coli strain RDEC-1 AF/R1 endogenous fimbrial glycoconjugate receptor molecules in rabbit small intestine, Infect. Immun. (2001) 69:640-649.

[95] Salajka E., Salajkova Z., Alexa P., Hornich M., Colonization factor different from K88, K99, F41 and 987P in enterotoxigenic Escherichia coli strains isolated from postweaning diarrhoea in pigs, Vet. Microbiol. (1992) 32:163-175.

[96] Senerwa D., Olsvik O., Mutanda L.N., Lindqvist K.J., Gathuma J.M., Fossum K., Wachsmuth K., Enteropathogenic Escherichia coli serotype O111:HNT isolated from preterm neonates in Nairobi, Kenya, J. Clin. Microbiol. (1989) 27:1307-1311.

[97] Sherlock O., Schembri M.A., Reisner A., Klemm P., Novel roles for the AIDA adhesin from diarrheagenic Escherichia coli: cell aggregation and biofilm formation, J. Bacteriol. (2004) 186:8058-8065.

[98] Smeds A., Hemmann K., Jakava-Viljanen M., Pelkonen S., Imberechts H., Palva A., Characterization of the adhesin of Escherichia coli F18 fimbriae, Infect. Immun. (2001) 69:7941-7945.
[99] Sohel I., Puente J.L., Murray W.J., Vuopio-Varkila J., Schoolnik G.K., Cloning and characterization of the bundle-forming pilin gene of enteropathogenic Escherichia coli and its distribution in Salmonella serotypes, Mol. Microbiol. (1993) 7:563-575.

[100] Sohel I., Puente J.L., Ramer S.W., Bieber D., Wu C.Y., Schoolnik G.K., Enteropathogenic Escherichia coli: identification of a gene cluster coding for bundleforming pilus morphogenesis, J. Bacteriol. (1996) 178: 2613-2628

[101] Stevens M.P., van Diemen P.M., Frankel G., Phillips A.D., Wallis T.S., Efa1 influences colonization of the bovine intestine by shiga toxin-producing Escherichia coli serotypes O5 and O111, Infect. Immun. (2002) 70:5158-5166.

[102] Stevens M.P., Roe A.J., Vlisidou I., van Diemen P.M., La Ragione R.M., Best A., et al., Mutation of toxB and a truncated version of the efa-1 gene in Escherichia coli $\mathrm{O} 157: \mathrm{H7}$ influences the expression and secretion of locus of enterocyte effacement-encoded proteins but not intestinal colonization in calves or sheep, Infect. Immun. (2004) 72:5402-5411.

[103] Stone K.D., Zhang H.Z., Carlson L.K., Donnenberg M.S., A cluster of fourteen genes from enteropathogenic Escherichia coli is sufficient for the biogenesis of a type IV pilus, Mol. Microbiol. (1996) 20:325-337.

[104] Szalo I.M., Goffaux F., Pirson V., Pierard D., Ball H., Mainil J., Presence in bovine enteropathogenic (EPEC) and enterohaemorrhagic (EHEC) Escherichia coli of genes encoding for putative adhesins of human EHEC strains, Res. Microbiol. (2002) 153:653-658.

[105] Tarr P.I., Bilge S.S., Vary J.C. Jr, Jelacic S., Habeeb R.L., Ward T.R., et al., Iha: a novel Escherichia coli O157:H7 adherence-conferring molecule encoded on a recently acquired chromosomal island of conserved structure, Infect. Immun. (2000) 68:1400-1407.

[106] Tatarczak M., Wieczorek K., Posse B., Osek J., Identification of putative adhesin genes in shigatoxigenic Escherichia coli isolated from different sources, Vet. Microbiol. (2005) 110:77-85.

[107] Tatsuno I., Horie M., Abe H., Miki T., Makino K., Shinagawa H., et al., toxB gene on pO157 of enterohemorrhagic Escherichia coli O157:H7 is required for full epithelial cell adherence phenotype, Infect. Immun. (2001) 69:6660-6669.

[108] Tatsuno I., Mundy R., Frankel G., Chong Y., Phillips A.D., Torres A.G., Kaper J.B., The lpf gene cluster for long polar fimbriae is not involved in adherence of enteropathogenic Escherichia coli or virulence of Citrobacter rodentium, Infect. Immun. (2006) 74:265272.

[109] Tiels P., Verdonck F., Smet A., Goddeeris B., Cox E., The F18 fimbrial adhesin FedF is highly conserved among F18 + Escherichia coli isolates, Vet. Microbiol. (2005) 110:277-283. 
[110] Tiels P., Verdonck F., Coddens A., Goddeeris B., Cox E., The excretion of F18 + E. coli is reduced after oral immunisation of pigs with a FedF and F4 fimbriae conjugate, Vaccine (2008) 26:2154-2163.

[111] Tobe T., Sasakawa C., Species-specific cell adhesion of enteropathogenic Escherichia coli is mediated by type IV bundle-forming pili, Cell. Microbiol. (2002) 4:29-42.

[112] Toma C., Martìnez Espinosa E., Song T., Miliwebsky E., Chinen I., Iyoda S., et al., Distribution of putative adhesins in different seropathotypes of Shiga toxinproducing Escherichia coli, J. Clin. Microbiol. (2004) 42:4937-4946.

[113] Toma C., Higa N., Iyoda S., Rivas M., Iwanaga M., The long polar fimbriae genes identified in Shiga toxinproducing Escherichia coli are present in other diarrheagenic $E$. coli and in the standard E. coli collection of reference (ECOR) strains, Res. Microbiol. (2006) 157:153-161.

[114] Toma C., Nakasone N., Miliwebsky E., Higa N., Rivas M., Suzuki T., Differential adherence of Shiga toxin-producing Escherichia coli harboring saa to epithelial cells, Int. J. Med. Microbiol. (2008) 298:571-578.

[115] Torres A.G., Giron J.A., Perna N.T., Burland V., Blattner F.R., Avelino-Flores F., Kaper J.B., Identification and characterization of lpfABCC'DE, a fimbrial operon of enterohemorrhagic Escherichia coli O157:H7, Infect. Immun. (2002) 70:5416-5427.

[116] Torres A.G., Perna N.T., Burland V., Ruknudin A., Blattner F.R., Kaper J.B., Characterization of Cah, a calcium-binding and heat-extractable autotransporter protein of enterohaemorrhagic Escherichia coli, Mol. Microbiol. (2002) 45:951-966.

[117] Torres A.G., Kanack K.J., Tutt C.B., Popov V., Kaper J.B., Characterization of the second long polar (LP) fimbriae of Escherichia coli $\mathrm{O} 157: \mathrm{H} 7$ and distribution of LP fimbriae in other pathogenic E. coli strains, FEMS Microbiol. Lett. (2004) 238:333-344.

[118] Tozzoli R., Caprioli A., Morabito S., Detection of toxB, a plasmid virulence gene of Escherichia coli O157, in enterohemorrhagic and enteropathogenic E. coli, J. Clin. Microbiol. (2005) 43:4052-4056.

[119] Trabulsi L.R., Keller R., Tardelli Gomes T.A., Typical and atypical enteropathogenic Escherichia coli, Emerg. Infect. Dis. (2002) 8:508-513.

[120] Vallance B.A., Finlay B.B., Exploitation of host cells by enteropathogenic Escherichia coli, Proc. Natl. Acad. Sci. USA (2000) 97:8799-8806.

[121] van Diemen P.M., Dziva F., Stevens M.P., Wallis T.S., Identification of enterohemorrhagic Escherichia coli $\mathrm{O} 26: \mathrm{H}-$ genes required for intestinal colonization in calves, Infect. Immun. (2005) 73:1735-1743.

[122] van Duijkeren E., van Asten A.J., Gaastra W., Characterization of Escherichia coli isolated from adult horses with and without enteritis, Vet. Q. (2000) 22:162166.

[123] Verdonck F., Tiels P., van Gog K., Goddeeris B.M., Lycke N., Clements J., Cox E., Mucosal immunization of piglets with purified F18 fimbriae does not protect against F18 + Escherichia coli infection, Vet. Immunol. Immunopathol. (2007) 120:69-79.

[124] Wells J.G., Davis B.R., Wachsmuth I.K., Riley L.W., Remis R.S., Sokolow R., Morris G.K., Laboratory investigation of hemorrhagic colitis outbreaks associated with a rare Escherichia coli serotype, J. Clin. Microbiol. (1983) 18:512-520.

[125] Wells T.J., Sherlock O., Rivas L., Mahajan A., Beatson S.A., Torpdahl M., et al., EhaA is a novel autotransporter protein of enterohemorrhagic Escherichia coli $\mathrm{O} 157: \mathrm{H} 7$ that contributes to adhesion and biofilm formation, Environ. Microbiol. (2008) 10:589-604.

[126] Wieler L.H., Bauerfeind R., STEC as a veterinary problem. Diagnostics and prophylaxis in animals, Methods Mol. Med. (2003) 73:75-89.

[127] Xicohtencatl-Cortes J., Monteiro-Neto V., Ledesma M.A., Jordan D.M., Francetic O., Kaper J.B., et al., Intestinal adherence associated with type IV pili of enterohemorrhagic Escherichia coli O157:H7, J. Clin. Invest. (2007) 117:3519-3529.

[128] Xicohtencatl-Cortes J., Monteiro-Neto V., Saldana Z., Ledesma M.A., Puente J.L., Giron J.A., The type 4 pili of enterohemorrhagic Escherichia coli O157:H7 are multi-purpose structures with pathogenic attributes, J. Bacteriol. (2009) 191:411-421.

[129] Yokoyama H., Hashi T., Umeda K., Icatlo F.C. Jr, Kuroki M., Ikemori Y., Kodama Y., Effect of oral egg antibody in experimental F18 + Escherichia coli infection in weaned pigs, J. Vet. Med. Sci. (1997) 59:917-921.

[130] Zhao L., Chen X., Xu X., Song G., Liu X., Analysis of the AIDA-I gene sequence and prevalence in Escherichia coli isolates from pigs with post-weaning diarrhoea and oedema disease, Vet. J. (2009) 180:124 129.

[131] Zuniga A., Yokoyama H., Albicker-Rippinger P., Eggenberger E., Bertschinger H.U., Reduced intestinal colonisation with F18-positive enterotoxigenic Escherichia coli in weaned pigs fed chicken egg antibody against the fimbriae, FEMS Immunol. Med. Microbiol (1997) 18:153-161.

[132] Zweifel C., Schumacher S., Blanco M., Blanco J.E., Tasara T., Blanco J., Stephan R., Phenotypic and genotypic characteristics of non-O157 Shiga toxin-producing Escherichia coli (STEC) from Swiss cattle, Vet. Microbiol. (2005) 105:37-45.

[133] Zweifel C., Schumacher S., Beutin L., Blanco J., Stephan R., Virulence profiles of Shiga toxin 2e-producing Escherichia coli isolated from healthy pig at slaughter, Vet. Microbiol. (2006) 117:328-332. 